\title{
Analisis Pengendalian Mutu Kadar Air Teh Hitam pada Industri Pengolahan Teh
}

\author{
Gustiarini Rika Putri ${ }^{1}$, Rizki Fadhillah Lubis ${ }^{1}$, Asri Yenita ${ }^{1}$ \\ ${ }^{I}$ Jurusan Teknik Industri Agro, Politeknik ATI Padang, Jl. Bungo Pasang Tabing Padang 25171, Indonesia
}

\section{ARTICLE INFORMATION}

Received: November 30, 2021

Revised: December 30, 2021

Available online: December 31, 2021

\section{KEYWORDS}

Moisture Content, Quality Control, Tea Quality

\section{CORRESPONDENCE}

Name: Rizki Fadhillah Lubis

E-mail: rizkylubis@poltekatipdg.ac.id

\section{A $\quad$ B $\quad \mathbf{S}$ T $\mathbf{R}$ A $\mathbf{C}$ T}

Quality control is intended to maintain and improve quality and maintain the safety of the products produced. This study uses Statistical Process Control by using several tools such as check sheets, control charts and fishbone diagrams to determine the cause of the decline in quality in tea with the aim that the next process can minimize the level of product quality decline. This study aims to determine the dominant cause of the decline in tea quality when viewed from the water content in tea. Based on the results of the study, it can be seen that the dominant cause of the decline in tea quality is the highwater content of dry tea. This type of deterioration can be caused by human error and other factors such as machine condition, raw materials and process monitoring.

\section{PENDAHULUAN}

Indonesia menjadi salah satu produsen teh terbesar dunia dengan total produk mencapai 125 ribu ton pada 2016 yang berkontribusi sebesar $3 \%$ dari total produksi teh dunia. Kualitas produk teh merupakan faktor utama untuk meningkatkan daya saing produk teh Indonesia [1]. Mutu teh merupakan kumpulan sifat yang dimiliki oleh teh, baik fisik maupun kimia. Keduanya telah dimiliki sejak berupa pucuk teh maupun diperoleh sebagai akibat dari teknik penanganan maupun pengolahan yang dilakukan. Sebab itu, usaha pengendalian mutu teh telah dilakukan sejak teh ditanam, dipetik, diangkut ke pabrik, selama diolah, dan sesudah pengolahan [2]. Teh dihasilkan dari pucuk dengan 2-3 daun muda $(\mathrm{P}+2$ atau $\mathrm{P}+3$ ) yang selanjutnya diolah sehingga dihasilkan berbagai jenis teh. Pada prinsipnya proses pengolahan teh dibagi dalam tiga jenis; teh tanpa oksidasi (teh putih, teh hijau), teh semi oksidasi (teh oolong), dan teh dengan proses oksidasi (teh hitam) [3].

Dalam rangka mengarahkan proses pengolahan agar diperoleh hasil yang sesuai dengan standar mutu yang telah ditetapkan, maka pada setiap tahapan pengolahan selalu dilaksanakan pemeriksaan mutu bahan olah maupun kondisi pengolahan yang mengacu pada beberapa metode pengujian. Dengan metode pengujian yang akurat diharapkan bahwa pengendalian proses berjalan efektif sehingga tujuan proses yang diharapkan dapat tercapai. Sehingga untuk mendapatkan mutu yang baik perlu penerapan pengendalian mutu sejak dari bahan baku di kebun, penanganan, pengolahan di pabrik sampai produk tersebut siap dikonsumsi. Dengan pengolahan yang tepat, kualitas dasar dari pucuk akan dapat dipertahankan.

Teh hitam dihasilkan melalui proses pelayuan dan dilanjutkan dengan oksidasi enzimatis. Pada pengolahan teh hitam terdapat dua jenis yaitu sistem ortodoks dan sistem Crushing-Tearing-Curling (CTC) [4]. Salah satu paramter mutu teh hitam adalah kadar air. Kadar air teh hitam cendrung rendah, sehingga ini menjadi salah satu penyebab teh hitam bisa disimpan lebih lama. Untuk mendapatkan kadar air teh hitam yang rendah adalah proses pengeringan daun teh pada stasiun pengeringan. Kondisi yang sering tejadi adalah kadar air teh hitam yang diatas standar mutu kadar air teh hitam yang ditetapkan perusahaan atau kadar air teh hitam yang dihasilkan cendrung tinggi. Menurut Rosida dan Amalia [5], pengendalian produksi the hitam dapat dilakukan dengan memperhatikan aspek-aspek seperti pengendalian mutu bahan baku, pengendalian mutu proses pengolahan dan pengendalian mutu produk akhir. 
Adapun tujuan dari penelitian ini adalah untuk mengetahui faktor-faktor yang mempengaruhi perubahan mutu kadar air teh hitam dan cara pengendaliannya agar teh hitam yang diproduksi dapat memenuhi standar perusahaan yang telah ditetapkan pada salah satu perusahaan industri pengolahan teh. Penelitian menggunakan metode Statistical Process Control yang merupakan teknik yang digunakan untuk menyelesaikan masalah, memonitor, menganalisis, mengelola, mengendalikan dan memperbaiki produk melalui proses penggunaan metode statistik. Penggunaan Statistical Process Control dapat menghasilkan perbaikan yang berkesinambungan dan diperoleh perbaikan maksimal sehingga tidak mengkibatkan kerugian pada perusahaan.

\section{Statistical Quality Control}

Statistik merupakan teknik pengambilan keputusan tentang suatu proses atau populasi berdasarkan pada suatu analisa informasi yang terkandung di dalam suatu sampel dari populasi. Metode statistik memegang peranan penting dalam jaminan kualitas. Metode statistik memberikan cara-cara pokok dalam pengambilan sampel produk, pengujian serta evaluasi di dalam data yang digunakan untuk mengendalikan [6]. Menurut Heizer dan Render [7] pengendalian mutu statistik adalah proses yang digunakan untuk mengawasi standar, membuat pengukuran dan mengambil tindakan perbaikan selagi sebuah produk atau jasa yang diproduksi. Menurut Assauri [8] Statistical Quality Control adalah suatu sistem yang dikembangkan untuk menjaga standar yang uniform dari kualitas hasil produksi, pada tingkat biaya yang minimum dan merupakan bantuan untuk mencapai efisiensi. Dengan kata lain, pengendalian kualitas statistika menjadi satu teknik yang dirancang untuk mengevaluasi kualitas ditinjau dari sisi kesesuaian dengan spesifikasinya.

Pengendalian kualitas proses statistik (statistical process control) merupakan teknik penyelesaian masalah yang digunakan sebagai pemonitor, pengendali, penganalisis, pengelola, dan memperbaiki proses mengggunakan metode-metode statistik. Filosofi pada konsep pengendalian kualitas proses statistik atau lebih dikenal dengan pengendalian kualitas statistik (statistical quality control) adalah output pada proses atau pelayanan dapat dikemukakan ke dalam pengendalian statistik melalui alat-alat manajemen dan tindakan perancangan [9].

Statistik proses kontrol ini dibuat dengan tujuan untuk mendeteksi penyebab khusus yang mengakibatkan terjadinya kecacatan atau proses diluar kontrol sedini mungkin sehingga kualitas produk dapat dipertahankan. Statistik proses kontrol ini terdiri dari 7 alat pengendalian kualitas yang lebih dikenal dengan nama seven tools quality, yaitu: [10]
a. Lembar Pemeriksaan (Check Sheet)
b. Histogram
c. Diagram Pareto
d. Stratifikasi
e. Diagram Pencar (Scatter Diagram)
f. Hubungan Sebab Akibat
g. Peta Kendali (Control Chart)

\section{METODOLOGI}

Penelitian ini dilakukan di salah satu industri pengolahan teh pada perusahaan BUMN. Metode yang digunakan dalam penelitian ini adalah metode Statistical Process Control (SPC). Pada penelitian ini, alat bantu yang digunakan hanya beberapa teknik analisis yaitu Check Sheet, Peta Kendali dan Diagram Sebab Akibat (fishbone). Adapun langkah-langkah analisis data yang dilakukan adalah:

\section{Check Sheet}

Lembar Check Sheet itu diperoleh dari data produksi dan data produk cacat dari perusahaan yang kemudian diolah menjadi tabel yang terukur. Tujuannya untuk memudahkan dalam memahami data

\section{Peta Kendali}

Mengidentifikasi setiap kondisi yang tidak terkendali secara statistik dengan control chart. Peta kendali yang digunakan dalam control chart atau peta kendali pada penelitian ini yaitu peta kendali $\mathrm{X}$ dan $\mathrm{R}$. Adapun langkah-langkah dalam membuat peta kendali X dan R adalah sebagai berikut:

a) Menentukan ukuran subgrup

b) Membuat peta kendali $\mathrm{X}$ menggunakan rata-rata $\mathrm{X}$ dengan rumus:

$$
\overline{\mathrm{x}}=\frac{\sum_{i=1}^{g} \bar{x} i}{g}
$$

c) Mentukan garis tengah $\mathrm{R}$ yakni rentang rata-rata dengan menggunakan rumus:

$$
\overline{\mathrm{R}}=\frac{\sum_{i=1}^{g} R i}{g}
$$

d) Menghitung batas kendali dari peta kendali X, dimana:

Garis pusat $\mathrm{CL}=\overline{\overline{\mathrm{x}}}$

Uper Control Limit dengan rumus:

$\mathrm{UCL}=\overline{\mathrm{X}}+(\mathrm{A} 2 * \overline{\mathrm{R}})$

Lower Control Limit dengan rumus:

$\mathrm{LCL} \quad=\overline{\mathrm{X}}-(\mathrm{A} 2 * \overline{\mathrm{R}})$

e) Mengitung batas kendali untuk peta kendali $R$

$\mathrm{UCL}=\mathrm{D} 4 . \mathrm{R}$

$\mathrm{LCL}=\mathrm{D} 3 . \mathrm{R}$

f) Memplot titik-titik $X$ dan $R$ pada peta yang terbentuk 
g) Memplot data $X$ dan $R$ pada peta kendali $X$ dan $\mathrm{R}$ serta mengamati apakah data tersebut berada dalam pengendalian atau tidak.

\section{Diagram Sebab Akibat}

Mencari faktor penyebab yang dominan dengan menggunakan diagram sebab akibat (cause and effect diagram).

\section{Membuat Usulan Perbaikan}

Membuat usulan perbaikan berdasarkan data Sebab Akibat terjadinya kerusakan produk

\section{HASIL DAN PEMBAHASAN}

\section{Check Sheet}

Data yang digunakan dalam penelitian ini adalah data sampel pengujian kadar air pucuk basah dan kadar air kering pada bulan Maret 2021. Data kadar air pucuk basah perharinya dengan sampel X1 diambil di shift pertama jam 07.00 WIB dan sampel X2 diambil di shift kedua jam 14.00 WIB, sedangkan data kadar air teh kering perharinya dengan sampel X1 diambil di shiftpertama pada jam 09.00 WIB, dan sampel X2 diambil di shift kedua pada jam 14.00 WIB. Berikut pengujian kadar air dapat di lihat pada Tabel 1.

Untuk mendapatkan produk yang berkualitas maka perusahaan melakukan penetapan standarisasi terhadap mutu produk yang dihasilkan. Standar kadar air pucuk basah pada stasiun pelayuan adalah 54\%-58\%, sedangkan standar kadar air teh kering pada proses pengeringan yang ditetapkan adalah 2.4\%-3.0\%.

Tabel 1. Data Sampel Pengujian Kadar Air Pucuk Basah dan Kadar Air Kering Bulan Maret 2021

\begin{tabular}{cccccc}
\hline \multirow{2}{*}{ No } & \multirow{2}{*}{ Tanggal } & \multicolumn{2}{c}{ Pucuk Basah $(\%)$} & \multicolumn{2}{c}{ Kadar Air Kering $(\%)$} \\
\cline { 3 - 5 } & & X1 $(\%)$ & X2 $(\%)$ & X1 $(\%)$ & X2 $(\%)$ \\
\hline 1. & 02 Maret 2021 & 55.5 & 58.6 & 2.80 & 3.00 \\
2. & 03 Maret 2021 & 54.0 & 56.3 & 2.50 & 2.60 \\
3. & 04 Maret 2021 & 55.6 & 58.2 & 2.40 & 2.30 \\
4. & 05 Maret 2021 & 58.0 & 57.0 & 2.40 & 2.50 \\
5. & 06 Maret 2021 & 60.0 & 58.3 & 2.30 & 2.50 \\
6. & 07 Maret 2021 & 55.4 & 57.0 & 2.40 & 2.50 \\
7. & 09 Maret 2021 & 56.8 & 59.4 & 2.50 & 2.40 \\
8. & 10 Maret 2021 & 58.9 & 55.0 & 2.90 & 3.00 \\
9. & 11 Maret 2021 & 58.0 & 58.5 & 2.80 & 3.00 \\
10. & 12 Maret 2021 & 55.9 & 56.9 & 2.70 & 2.80 \\
11. & 13 Maret 2021 & 62.5 & 60.5 & 2.20 & 2.30 \\
12. & 14 Maret 2021 & 59.0 & 58.5 & 2.60 & 2.30 \\
13. & 16 Maret 2021 & 61.0 & 57.6 & 2.60 & 2.50 \\
14. & 17 Maret 2021 & 68.0 & 64.5 & 2.50 & 2.60 \\
15. & 18 Maret 2021 & 57.4 & 58.0 & 2.70 & 2.60 \\
16. & 19 Maret 2021 & 56.6 & 60.3 & 2.50 & 2.60 \\
17. & 20 Maret 2021 & 53.5 & 56.0 & 2.50 & 2.60 \\
18. & 21 Maret 2021 & 67.3 & 65.3 & 2.90 & 3.00 \\
19. & 23 Maret 2021 & 55.6 & 54.0 & 2.60 & 2.40 \\
20. & 24 Maret 2021 & 60.9 & 59.1 & 2.60 & 2.50 \\
21. & 25 Maret 2021 & 59.0 & 58.0 & 2.50 & 2.30 \\
22. & 25 Maret 2021 & 58.5 & 56.7 & 3.00 & 2.90 \\
23. & 26 Maret 2021 & 57.4 & 56.0 & 2.70 & 2.90 \\
24. & 27 Maret 2021 & 56.9 & 59.5 & 2.60 & 2.90 \\
25. & 28 Maret 2021 & 65.0 & 68.0 & 2.50 & 2.40 \\
\hline
\end{tabular}

Sumber: Industri Pengolahan Teh Hitam, 2021 


\section{Peta Kendali}

Untuk membuat peta kendali $\mathrm{X}$ deangan mencari nilai rata-rata. Nilai rata-rata yang juga merupakan garis sentral didapatkan dengan:

$\overline{\mathrm{x}}=\frac{\sum_{i=1}^{g} \overline{x i}}{g}$

$\overline{\mathrm{x}}=\frac{1467}{25}=58,7$

Penentuan garis tengah $\mathrm{R}$ yakni rentang rata-rata adalah sebagai berikut :

$\overline{\mathrm{R}}=\frac{\sum_{i=1}^{g} R i}{g}$

$\overline{\mathrm{R}}=\frac{51,7}{25}=2,1$

Nilai A2 $=1,88$, D3 = 0, dan D4 = 3,269 untuk ukuran subgroup 2 didapat dari tabel faktor A dan D pembentuk peta kendali. Batas kendali X untuk bulan Maret 2021 adalah :
Garis pusat $\mathrm{CL}=\overline{\overline{\mathrm{x}}}$

Uper Control Limit (Batas Kontrol Atas)

$$
\begin{aligned}
\mathrm{UCL} & =\overline{\mathrm{X}}+(\mathrm{A} 2 * \overline{\mathrm{R}}) \\
& =58,7+(1,88 * 2.1) \\
& =58,7+3.948 \\
& =62,6
\end{aligned}
$$

Lower Control Limit (Batas Kontrol Bawah)

$$
\begin{aligned}
\mathrm{LCL} & =\overline{\mathrm{X}}-(\mathrm{A} 2 * \overline{\mathrm{R}}) \\
& =58,7-(1,88 * 2.1) \\
& =58,7-3.948 \\
& =54,8
\end{aligned}
$$

Menghitung UCL dan LCL untuk peta kendali R adalah:

\begin{tabular}{|c|c|c|c|c|c|c|c|c|c|c|c|}
\hline \multirow{2}{*}{ No. } & \multirow{2}{*}{ Tanggal } & \multicolumn{2}{|c|}{ Sampel (\%) } & \multirow{2}{*}{ Xbar } & \multirow{2}{*}{$\mathrm{R}$} & \multicolumn{3}{|c|}{ X } & \multicolumn{3}{|c|}{$\mathrm{R}$} \\
\hline & & $\mathrm{X} 1$ & $\mathrm{X} 2$ & & & $\mathrm{CL}$ & $\mathrm{UCL}$ & LCL & $\mathrm{CL}$ & UCL & LCL \\
\hline 1. & $02 / 03 / 21$ & 55.5 & 58.6 & 57.1 & 3.1 & 58.7 & 62.6 & 54.8 & 2.1 & 6.8 & 0 \\
\hline 2. & $03 / 03 / 21$ & 54.0 & 56.3 & 55.2 & 2.3 & 58.7 & 62.6 & 54.8 & 2.1 & 6.8 & 0 \\
\hline 3. & 04/03/21 & 55.6 & 58.2 & 56.9 & 2.6 & 58.7 & 62.6 & 54.8 & 2.1 & 6.8 & 0 \\
\hline 4. & $05 / 03 / 21$ & 58.0 & 57.0 & 57.5 & 1.0 & 58.7 & 62.6 & 54.8 & 2.1 & 6.8 & 0 \\
\hline 5. & $06 / 03 / 21$ & 60.0 & 58.3 & 59.2 & 1.7 & 58.7 & 62.6 & 54.8 & 2.1 & 6.8 & 0 \\
\hline 6. & $07 / 03 / 21$ & 55.4 & 57.0 & 56.2 & 1.6 & 58.7 & 62.6 & 54.8 & 2.1 & 6.8 & 0 \\
\hline 7. & 09/03/21 & 56.8 & 59.4 & 58.1 & 2.6 & 58.7 & 62.6 & 54.8 & 2.1 & 6.8 & 0 \\
\hline 8. & $10 / 03 / 21$ & 58.9 & 55.0 & 57.0 & 3.9 & 58.7 & 62.6 & 54.8 & 2.1 & 6.8 & 0 \\
\hline 9. & $11 / 03 / 21$ & 58.0 & 58.5 & 58.3 & 0.5 & 58.7 & 62.6 & 54.8 & 2.1 & 6.8 & 0 \\
\hline 10. & $12 / 03 / 21$ & 55.9 & 56.9 & 56.4 & 1.0 & 58.7 & 62.6 & 54.8 & 2.1 & 6.8 & 0 \\
\hline 11. & $13 / 03 / 21$ & 62.5 & 60.5 & 61.5 & 2.0 & 58.7 & 62.6 & 54.8 & 2.1 & 6.8 & 0 \\
\hline 12. & $14 / 03 / 21$ & 59.0 & 58.5 & 58.8 & 0.5 & 58.7 & 62.6 & 54.8 & 2.1 & 6.8 & 0 \\
\hline 13. & $16 / 03 / 21$ & 61.0 & 57.6 & 59.3 & 3.4 & 58.7 & 62.6 & 54.8 & 2.1 & 6.8 & 0 \\
\hline 14. & $17 / 03 / 21$ & 68.0 & 64.5 & 66.3 & 3.5 & 58.7 & 62.6 & 54.8 & 2.1 & 6.8 & 0 \\
\hline 15. & $18 / 03 / 21$ & 57.4 & 58.0 & 57.7 & 0.6 & 58.7 & 62.6 & 54.8 & 2.1 & 6.8 & 0 \\
\hline 16. & $19 / 03 / 21$ & 56.6 & 60.3 & 58.5 & 3.7 & 58.7 & 62.6 & 54.8 & 2.1 & 6.8 & 0 \\
\hline 17. & $20 / 03 / 21$ & 53.5 & 56.0 & 54.8 & 2.5 & 58.7 & 62.6 & 54.8 & 2.1 & 6.8 & 0 \\
\hline 18. & $21 / 03 / 21$ & 67.3 & 65.3 & 66.3 & 2.0 & 58.7 & 62.6 & 54.8 & 2.1 & 6.8 & 0 \\
\hline 19. & $23 / 03 / 21$ & 55.6 & 54.0 & 54.8 & 1.6 & 58.7 & 62.6 & 54.8 & 2.1 & 6.8 & 0 \\
\hline 20. & $24 / 03 / 21$ & 60.9 & 59.1 & 60.0 & 1.8 & 58.7 & 62.6 & 54.8 & 2.1 & 6.8 & 0 \\
\hline 21. & $25 / 03 / 21$ & 59.0 & 58.0 & 58.5 & 1.0 & 58.7 & 62.6 & 54.8 & 2.1 & 6.8 & 0 \\
\hline 22. & $26 / 03 / 21$ & 58.5 & 56.7 & 57.6 & 1.8 & 58.7 & 62.6 & 54.8 & 2.1 & 6.8 & 0 \\
\hline 23. & $27 / 03 / 21$ & 57.4 & 56.0 & 56.7 & 1.4 & 58.7 & 62.6 & 54.8 & 2.1 & 6.8 & 0 \\
\hline 24. & $28 / 03 / 21$ & 56.9 & 59.5 & 58.2 & 2.6 & 58.7 & 62.6 & 54.8 & 2.1 & 6.8 & 0 \\
\hline 25. & $30 / 03 / 21$ & 65.0 & 68.0 & 66.5 & 3.0 & 58.7 & 62.6 & 54.8 & 2.1 & 6.8 & 0 \\
\hline \multicolumn{4}{|c|}{ JUMLAH } & 1467.0 & 51.7 & & & & & & \\
\hline \multicolumn{4}{|c|}{ RATA-RATA } & 58.7 & 2.1 & & & & & & \\
\hline
\end{tabular}
Uper Control Limit (Batas Kontrol Atas)

$\mathrm{UCL}=\mathrm{D} 4 * \overline{\mathrm{R}}$

\begin{tabular}{|c|c|c|c|c|c|c|c|c|c|c|c|}
\hline \multirow{2}{*}{ No. } & \multirow{2}{*}{ Tanggal } & \multicolumn{2}{|c|}{ Sampel (\%) } & \multirow{2}{*}{ Xbar } & \multirow{2}{*}{$\mathrm{R}$} & \multicolumn{3}{|c|}{$X$} & \multicolumn{3}{|c|}{$\mathrm{R}$} \\
\hline & & $\mathrm{X} 1$ & $\mathrm{X} 2$ & & & $\mathrm{CL}$ & UCL & LCL & $\mathrm{CL}$ & UCL & LCL \\
\hline 1. & $02 / 03 / 21$ & 2.80 & 3.00 & 2.90 & 0.20 & 2.60 & 2.87 & 2.34 & 0.14 & 0.46 & 0 \\
\hline 2. & $03 / 03 / 21$ & 2.50 & 2.60 & 2.55 & 0.10 & 2.60 & 2.87 & 2.34 & 0.14 & 0.46 & 0 \\
\hline 3. & $04 / 03 / 21$ & 2.40 & 2.30 & 2.35 & 0.10 & 2.60 & 2.87 & 2.34 & 0.14 & 0.46 & 0 \\
\hline 4. & $05 / 03 / 21$ & 2.40 & 2.50 & 2.45 & 0.10 & 2.60 & 2.87 & 2.34 & 0.14 & 0.46 & 0 \\
\hline 5. & $06 / 03 / 21$ & 2.30 & 2.50 & 2.40 & 0.20 & 2.60 & 2.87 & 2.34 & 0.14 & 0.46 & 0 \\
\hline
\end{tabular}

$$
=3,269 * 2.1=6,8
$$

Lower Control Limit (Batas Kontrol Bawah)

$\mathrm{LCL}=\mathrm{D} 3 * \overline{\mathrm{R}}$

$$
=0 * 2,1=0
$$

Tabel 2 Perhitungan penetapan batas Peta Kendali Kadar Air Pucuk Basah Bulan Maret 2021

Tabel 3. Rekapitulasi Kadar Air Kering Bulan Maret 2021

84 Putri et al. 


\begin{tabular}{|c|c|c|c|c|c|c|c|c|c|c|c|}
\hline \multirow{2}{*}{ No. } & \multirow{2}{*}{ Tanggal } & \multicolumn{2}{|c|}{ Sampel (\%) } & \multirow{2}{*}{ Xbar } & \multirow{2}{*}{$\mathrm{R}$} & \multicolumn{3}{|c|}{$\mathrm{X}$} & \multicolumn{3}{|c|}{$\mathrm{R}$} \\
\hline & & $\mathrm{X} 1$ & $\mathrm{X} 2$ & & & $\mathrm{CL}$ & UCL & LCL & $\mathrm{CL}$ & UCL & LCL \\
\hline 6. & $07 / 03 / 21$ & 2.40 & 2.50 & 2.45 & 0.10 & 2.60 & 2.87 & 2.34 & 0.14 & 0.46 & 0 \\
\hline 7. & $09 / 03 / 21$ & 2.50 & 2.40 & 2.45 & 0.10 & 2.60 & 2.87 & 2.34 & 0.14 & 0.46 & 0 \\
\hline 8. & $10 / 03 / 21$ & 2.90 & 3.00 & 2.95 & 0.10 & 2.60 & 2.87 & 2.34 & 0.14 & 0.46 & 0 \\
\hline 9. & $11 / 03 / 21$ & 2.80 & 3.00 & 2.90 & 0.20 & 2.60 & 2.87 & 2.34 & 0.14 & 0.46 & 0 \\
\hline 10. & $12 / 03 / 21$ & 2.70 & 2.80 & 2.75 & 0.10 & 2.60 & 2.87 & 2.34 & 0.14 & 0.46 & 0 \\
\hline 11. & $13 / 03 / 21$ & 2.20 & 2.30 & 2.25 & 0.10 & 2.60 & 2.87 & 2.34 & 0.14 & 0.46 & 0 \\
\hline 12. & $14 / 03 / 21$ & 2.60 & 2.30 & 2.45 & 0.30 & 2.60 & 2.87 & 2.34 & 0.14 & 0.46 & 0 \\
\hline 13. & $16 / 03 / 21$ & 2.60 & 2.50 & 2.55 & 0.10 & 2.60 & 2.87 & 2.34 & 0.14 & 0.46 & 0 \\
\hline 14. & $17 / 03 / 21$ & 2.50 & 2.60 & 2.55 & 0.10 & 2.60 & 2.87 & 2.34 & 0.14 & 0.46 & 0 \\
\hline 15. & $18 / 03 / 21$ & 2.70 & 2.60 & 2.65 & 0.10 & 2.60 & 2.87 & 2.34 & 0.14 & 0.46 & 0 \\
\hline 16. & $19 / 03 / 21$ & 2.50 & 2.60 & 2.55 & 0.10 & 2.60 & 2.87 & 2.34 & 0.14 & 0.46 & 0 \\
\hline 17. & $20 / 03 / 21$ & 2.50 & 2.60 & 2.55 & 0.10 & 2.60 & 2.87 & 2.34 & 0.14 & 0.46 & 0 \\
\hline 18. & $21 / 03 / 21$ & 2.90 & 3.00 & 2.95 & 0.10 & 2.60 & 2.87 & 2.34 & 0.14 & 0.46 & 0 \\
\hline 19. & $23 / 03 / 21$ & 2.60 & 2.40 & 2.50 & 0.20 & 2.60 & 2.87 & 2.34 & 0.14 & 0.46 & 0 \\
\hline 20. & $24 / 03 / 21$ & 2.60 & 2.50 & 2.55 & 0.10 & 2.60 & 2.87 & 2.34 & 0.14 & 0.46 & 0 \\
\hline 21. & $25 / 03 / 21$ & 2.50 & 2.30 & 2.40 & 0.20 & 2.60 & 2.87 & 2.34 & 0.14 & 0.46 & 0 \\
\hline 22. & $26 / 03 / 21$ & 3.00 & 2.90 & 2.95 & 0.10 & 2.60 & 2.87 & 2.34 & 0.14 & 0.46 & 0 \\
\hline 23. & $27 / 03 / 21$ & 2.70 & 2.90 & 2.80 & 0.20 & 2.60 & 2.87 & 2.34 & 0.14 & 0.46 & 0 \\
\hline 24. & $28 / 03 / 21$ & 2.60 & 2.90 & 2.75 & 0.30 & 2.60 & 2.87 & 2.34 & 0.14 & 0.46 & 0 \\
\hline 25. & $30 / 03 / 21$ & 2.50 & 2.40 & 2.45 & 0.10 & 2.60 & 2.87 & 2.34 & 0.14 & 0.46 & 0 \\
\hline \multicolumn{4}{|c|}{ JUMLAH } & 65.05 & 3.50 & & & & & & \\
\hline \multicolumn{4}{|c|}{ RATA-RATA } & 2.60 & 0.14 & & & & & & \\
\hline
\end{tabular}

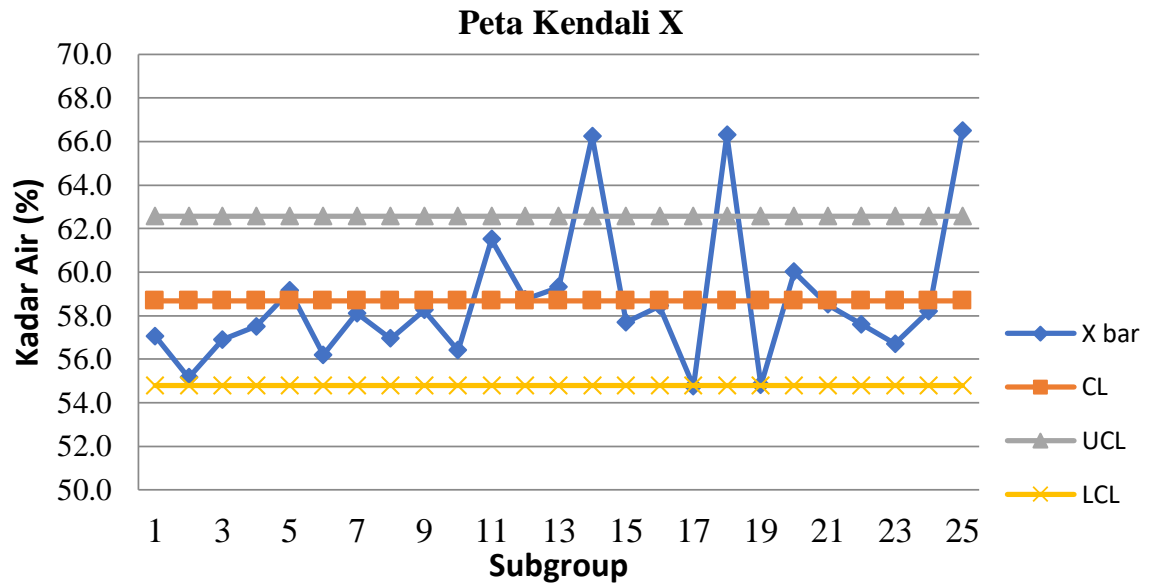

Gambar 1. Peta Kendali X Kadar Air Pucuk Basah Bulan Maret 2021

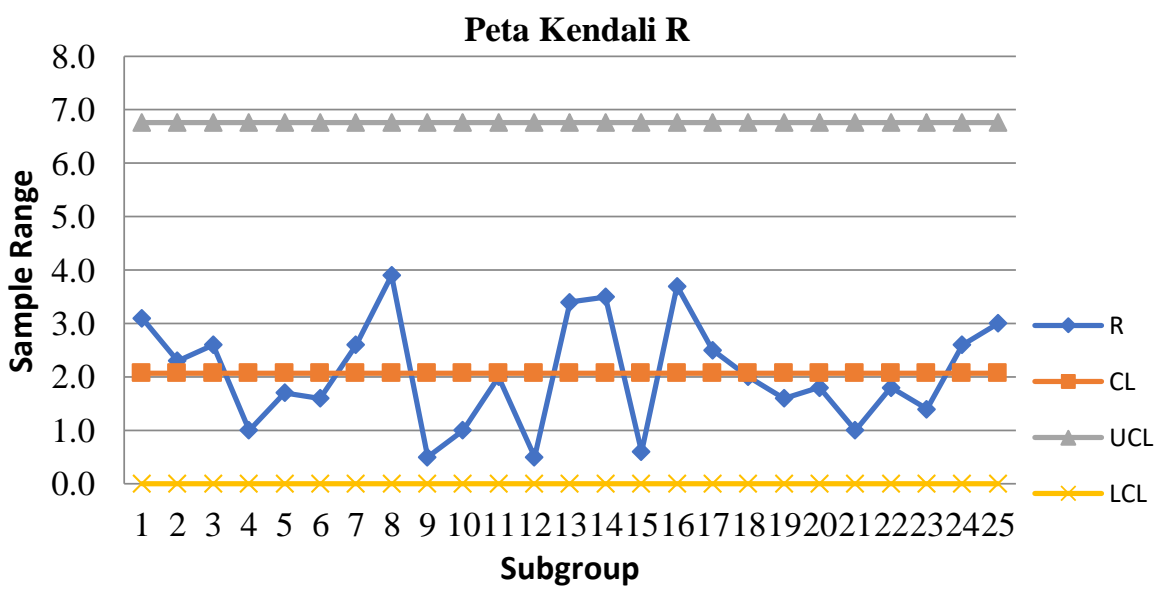

Gambar 2. Peta Kendali R Kadar Air Pucuk Basah Bulan Maret 2021 


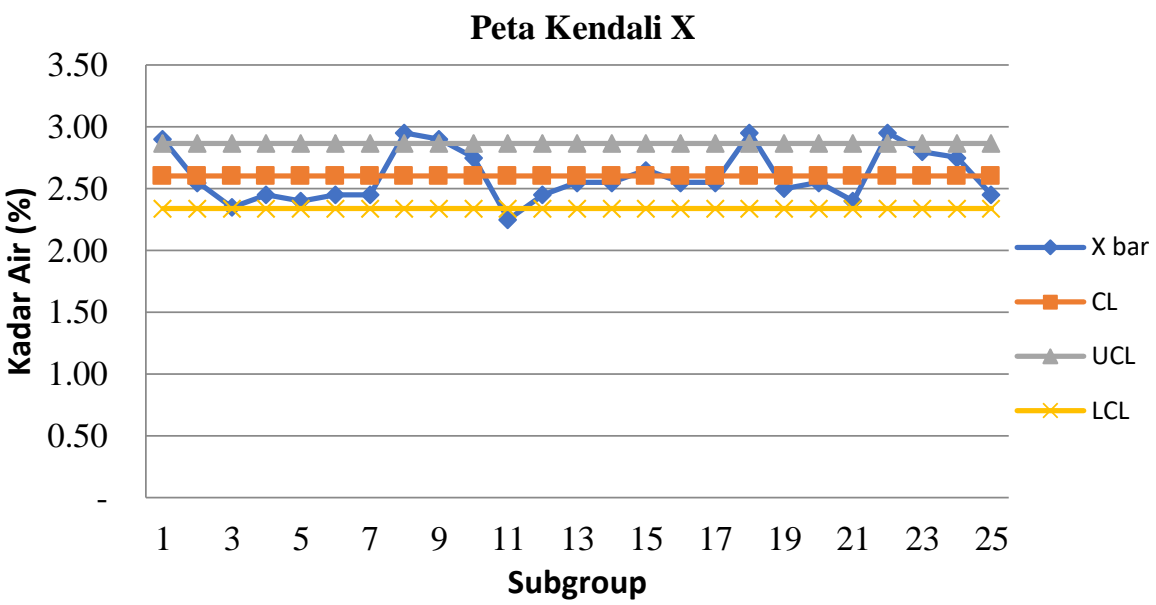

Gambar 3 Grafik Peta Kendali X Kadar Air Kering Bulan Maret 2021

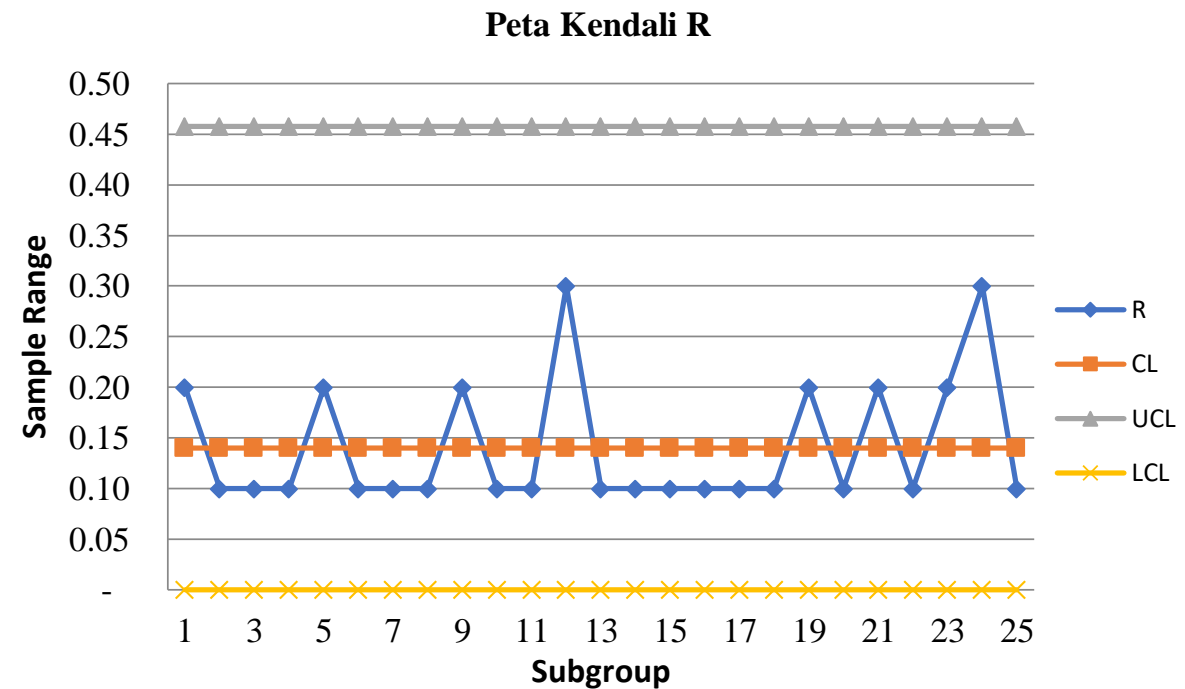

Gambar 4. Grafik Peta Kendali R Kadar Air Kering Bulan Maret 2021

Grafik peta kendali X dan R Kadar Air Pucuk Basah Bulan Maret 2021 diatas dapat dilihat bahwa pada peta kendali X terdapat enam data out of control pada titik nomor sampel ke-2, 14, 17, 18, 19 dan ke- 25. Terjadinya out of control pada peta kendali ini disebabkan oleh faktor bahan baku yang tidak memenuhi standar perusahaan, seperti daun kemerahan.

Sedangkan pada peta kendali R dari gambar 2 diketahui bahwa pada peta kendali $\mathrm{R}$ tidak ada terdapat data yang out of control. Ini dapat diartikan bahwa data tersebut terkendali secara statistik dan dapat dikatakan data seragam.

Setelah dilakukan pengolahan data dengan menggunakan metode Statistical Quality Control (SQC) maka dapat dilakukan analisis terhadap hasil pengolahan data dimana pada analisis peta kendali di atas dapat dilihat bahwa ada enam titik yang berada di luar batas kendali atau out of control pada UCL dan LCL peta kendali X, sedangkan pada peta kendali R tidak ada terdapat data out of control, sehingga dapat dikatakan bahwa pada peta kendali $\mathrm{R}$ dapat terkendali secara statistik atau dapat dikatakan data seragam. Pada analisis peta kendali pada gambar 4.3 dan gambar 4.4 di atas dapat dilihat bahwa ada tujuh titik yang berada di luar batas kendali atau out of control pada UCL dan LCL peta kendali X, sedangkan pada petakendali $\mathrm{R}$ tidak ada terdapat data out of control, sehingga dapat dikatakan bahwa pada peta kendali $\mathrm{R}$ dapat terkendali secara statistik atau dapat dikatakan data seragam.

Grafik peta kendali X dan R Kadar Air Kering Bulan Maret 2021 diatas dapat dilihat bahwa pada peta kendali $\mathrm{X}$ terdapat tujuh data out of control pada titik nomor sampel ke- 1, 3, 8, 9, 11, 14, 18, dan ke- 22. Terjadinya out of control pada peta kendali ini disebabkan oleh beberapa faktor dan faktor yang paling mempengaruhi terjadinya data out of control pada kadar air kering adalah faktor mesin dan bahan baku. Pada faktor mesin kurang optimumnya kerja pada mesin dryer dan mesin Heat Exchanger (HE) karena terjadinya kebocoran pada mesin 
HE yang tidak dapat bekerja secara stabil, sedangkan pada bahan baku masih banyak terdapat daun yang kemerahan dan kandungan air yang terdapat pada pucuk belum optimal. Sedangkan pada peta kendali $\mathrm{R}$ dari gambar 4 diketahui bahwa pada peta kendali R tidak ada terdapat data yang out of control. Ini dapat diartikan bahwa data tersebut terkendali secara statistik dan dapat dikatakan data seragam.

Dari hasil pengolahan kedua indikator kadar air diatas dapat kita analisa bahwa masih terdapat adanya data yang melewati batas kendali atau out of control, dimana hal ini di sebabkan oleh beberapa faktor seperti faktor bahan baku, manusia, metode dan faktor mesin. Berikut adalah data hasil rekapitulasi jenis uji karakteristik cacat pada proses pengolahan teh hitam pada bulan Maret 2021 dapat dilihat pada tabel 4 .

Tabel 4. Jumlah Data Diluar Batas Kendali Bulan Maret 2021

\begin{tabular}{|c|c|c|c|}
\hline \multirow[t]{2}{*}{ No } & \multirow{2}{*}{$\begin{array}{l}\text { Jenis Uji } \\
\text { Karakteristik }\end{array}$} & \multicolumn{2}{|c|}{$\begin{array}{c}\text { Jumlah Diluar Batas } \\
\text { Kendali }\end{array}$} \\
\hline & & X Chart & R Chart \\
\hline 1 & Kadar Air Pucuk Basah & 6 & 0 \\
\hline 2 & Kadar Air Kering & 7 & 0 \\
\hline
\end{tabular}

\section{Diagram Sebab Akibat}

Dari grafik terlihat bahwa jumlah data yang tidak terkendali terbesar yaitu dimulai dari kadar air kering lalu kadar air layu. Dengan demikian dilakukan analisa penyebab penyimpangan mutu yang paling dominan yaitu pada Kadar Air Teh Kering dengan menggunakan diagram fishbone.

Pada diagram fishbone ini kita dapat melihat faktorfaktor apa saja yang menjadi akar masalah dan yang mengakibatkan terjadinya penurun mutu teh pada proses pengolahan. Untuk itulah perlu dilakukan identifikasi masalah penyebab terjadinya penurunan mutu teh dengan menggunakan diagram sebab akibat. Identifikasi yang dilakukan adalah mencari akar masalah penyebab terjadinya kadar air teh kering yang rendah tinggi yang tidak sesuai dengan standar yang telah ditetapkan oleh perusahaan. Dengan cara menelususri akar-akar masalah yang terjadi mulai dari faktor material, manusia, mesin dan metodenya. Agar lebih jelasnya untuk mengetahui penyebab-penyebab tingginya kadar air teh kering pada pengolahan teh hitam dapat dilihat pada Gambar 3.

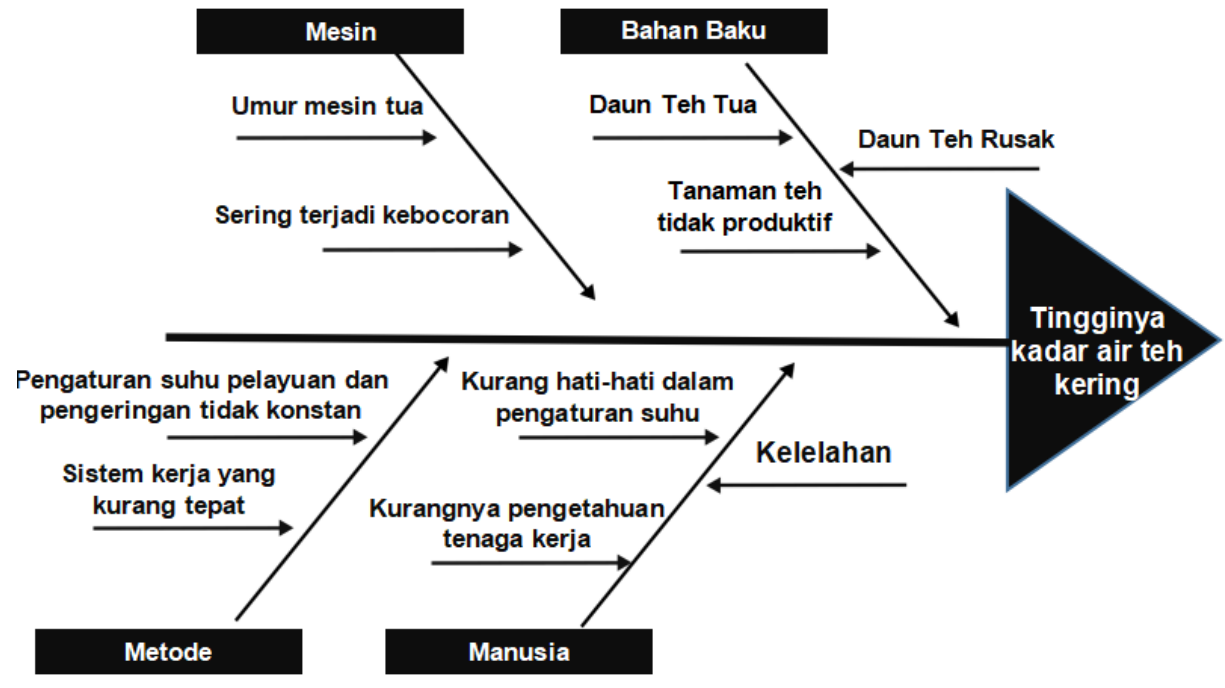

Gambar 3. Diagram Sebab Akibat

Tingginya kadar air teh kering berkaitan dengan proses pengeringan. Menurut Rosida dan Amalia [5], salah satu pengendalian mutu dalam proses pengolahan teh adalah proses pengeringan. Kapasitas alat pengering dipengaruhi oleh kondisi pucuk layu dan volume udara. Jika kadar air menunjukkan data yang lebih tinggi atau lebih rendah maka perlu diperhatikan faktor-faktor berikut:

1. Melakukan perubahan pada kecepatan alat

2. Melakukan perubahahan pada ketebalan hamparan

3. Memeriksa suhu inlet, outlet dan bubuk
4. Mengatur secara merata bubuk teh dari proses fermentasi

5. Membersihkan drier dari debu saat proses pengeringan selesai.

\section{Usulan Perbaikan}

Setelah mengetahui penyebab tingginya kadar air kering yang terjadi pada proses pengolahan teh hitam, maka tindakan selanjutnya adalah menyusun langkah-langkah perbaikan kadar air atau mutu teh hitam. 
Adapun langkah yang diambil untuk menyelesaikan masalah peningkatan mutu adalah dengan menggunakan diagram sebab akibat yang mana untuk mencari akar permasalahan rendah tinggi nya mutu. menggunakan diagram sebab-akibat dapat dilihat pada Tabel 3.

Tabel 3. Usulan Perbaikan Mutu Kadar Air Teh Hitam

\begin{tabular}{|c|c|c|c|c|c|}
\hline No & Masalah & Penyebab & Usulan Perbaikan & Siapa & Dimana \\
\hline 1 & $\begin{array}{l}\text { Bahan baku daun } \\
\text { teh rusak dan tua } \\
\text { serta kasar }\end{array}$ & $\begin{array}{l}\text { Penumpukan bahan baku } \\
\text { dalam } r \text { proses } \\
\text { pengangkutan dan stasiun } \\
\text { kerja }\end{array}$ & $\begin{array}{l}\text { Peningkatan pengawasan mandor } \\
\text { petik terhadap pemetik, dan } \\
\text { perbaikan sistem pengangkutan. }\end{array}$ & Semua operator & $\begin{array}{l}\text { Lapangan } \\
\text { atau kebun }\end{array}$ \\
\hline 2 & $\begin{array}{l}\text { Tanaman teh tidak } \\
\text { produktif }\end{array}$ & $\begin{array}{l}\text { Tidak dilakukan dilakukan } \\
\text { pemangkasan sesuai } \\
\text { periode dan penggantian } \\
\text { tanaman }\end{array}$ & $\begin{array}{l}\text { Mengganti atau memangkas } \\
\text { tanaman yang tidak produktif } \\
\text { dan penggantian tanaman baru } \\
\text { yang lebih baik. }\end{array}$ & Semua operator & $\begin{array}{l}\text { Lapangan } \\
\text { atau kebun }\end{array}$ \\
\hline 3 & $\begin{array}{l}\text { Operator sering } \\
\text { kelelahan selama } \\
\text { bekerja }\end{array}$ & $\begin{array}{l}\text { Kejenuhan akibat proses } \\
\text { berlangsung terus } \\
\text { menerus }\end{array}$ & $\begin{array}{l}\text { Memanfaatkan waktu istirahat } \\
\text { dengan sebaik mungkin }\end{array}$ & Semua operator & $\begin{array}{l}\text { Kebun dan } \\
\text { pabrik }\end{array}$ \\
\hline 4 & $\begin{array}{l}\text { Kurang hati-hati } \\
\text { dalam pemberian } \\
\text { suhu }\end{array}$ & $\begin{array}{l}\text { Operator tidak disiplin } \\
\text { degan SOP dan lalai } \\
\text { selama bekerja }\end{array}$ & $\begin{array}{l}\text { Lakukan pengontrolan dan } \\
\text { pemberian suhu yang sesuai, } \\
\text { serta adanya pengawasan dari } \\
\text { mandor proses. }\end{array}$ & Mekanik & $\begin{array}{l}\text { Stasiun } \\
\text { pelayuan }\end{array}$ \\
\hline 5 & $\begin{array}{l}\text { Mesin sudah banyak } \\
\text { yang tua dan } \\
\text { melewati umur } \\
\text { ekonomis }\end{array}$ & $\begin{array}{l}\text { Kurangnya perawatan } \\
\text { mesin secara berkala }\end{array}$ & $\begin{array}{l}\text { Lakukan perawatan mesin } \\
\text { secara rutin dan optimal seperti } \\
\text { pemberian oli pada mesin. }\end{array}$ & $\begin{array}{l}\text { Supervisor } \\
\text { produksi }\end{array}$ & $\begin{array}{l}\text { Stasiun } \\
\text { pengeringan }\end{array}$ \\
\hline 6 & $\begin{array}{l}\text { Sering terjadi } \\
\text { kebocoran pada } \\
\text { mesin Heat } \\
\text { Excanger }\end{array}$ & $\begin{array}{l}\text { Kurangnya perawatan } \\
\text { mesin secara berkala }\end{array}$ & $\begin{array}{l}\text { Melakukan pergantian } \\
\text { spearpart pada mesin, karena } \\
\text { apabila dilakukan penggantian } \\
\text { mesin akan mengeluarkan biaya } \\
\text { yang banyak }\end{array}$ & $\begin{array}{l}\text { Operator Mesin } \\
\text { Heat Exchanger }\end{array}$ & $\begin{array}{l}\text { Proses } \\
\text { pengolahan }\end{array}$ \\
\hline 7 & $\begin{array}{l}\text { Suhu pelayuan dan } \\
\text { pengeringan tidak } \\
\text { stabil }\end{array}$ & $\begin{array}{l}\text { Kurangnya pengawasan } \\
\text { mandor proses }\end{array}$ & $\begin{array}{l}\text { Melakukan monitoring dan } \\
\text { evaluasi terhadap peningkatan } \\
\text { mutu untuk memberikan } \\
\text { masukan kepada operator agar } \\
\text { dapat bertanggung jawab untuk } \\
\text { melakukan tindakan perbaikan } \\
\text { yang efektif. }\end{array}$ & $\begin{array}{l}\text { Operator stasiun } \\
\text { pelayuan dan } \\
\text { pengeringan }\end{array}$ & $\begin{array}{l}\text { Stasiun kerja } \\
\text { pelayuan dan } \\
\text { pengeringan }\end{array}$ \\
\hline 8 & $\begin{array}{l}\text { Sistem kerja yang } \\
\text { kurang tepat }\end{array}$ & $\begin{array}{l}\text { Kurangnya arahan dari } \\
\text { mandor }\end{array}$ & $\begin{array}{l}\text { Membuat manual mutu } \\
\text { berbasis pada kinerja sebagai } \\
\text { komitmen perusahaan dalam } \\
\text { kebijakan mutu yang harus } \\
\text { dicapai oleh setiap stasiun } \\
\text { kerja sesuai dengan kapasitas } \\
\text { dan kinerja msing-masing. }\end{array}$ & Seluruh operator & $\begin{array}{l}\text { Kebun dan } \\
\text { Pabrik }\end{array}$ \\
\hline
\end{tabular}

\section{KESIMPULAN}

Adapun faktor yang mempengaruhi kualitas produksi teh adalah Manusia, Bahan baku, Metode, Mesin. Sedangkan faktor yang paling dominan mempengaruhi kualitas produk teh adalah material (pucuk tua atau rusak) dan pemberian suhu yang tidak stabil pada tahan pengolahan (pelayuan dan pengeringan).

Upaya perbaikan yang paling tepat diterapkan adalah pada sistem pemetikan untuk meningkatkan kualitas bahan baku, pemberian suhu yang sesuai pada tahap pelayuan dan pengeringan. Perusahaan sebaiknya 
membuat grafik harian pengendalian kualitas untuk mempermudah memantau proses dari waktu ke waktu.

Perlu perbaikan dalam pengolahan, yaitu dilakukan pengontrolan serta pengawasan dari mulai tahapan panen, pasca panen sampai produksi untuk menghasilkan produk yang sesuai standar. Perlu reward dan punishment terhadap semua karyawan yang terlibat langsung dalam proses produksi.

\section{DAFTAR PUSTAKA}

[1] M. I. P. Atmaja, H. Maulana, Shabri, G. P. Riski, A. Fauziah dan S. Harianto. "EVALUASI KESESUAIAN MUTU PRODUK TEH DENGAN PERSYARATAN STANDAR NASIONAL INDONESIA". J. Standardisasi, vol. 23, no. 1, 2021, pp. 43-52.

[2] B. Kussriyanto. Meningkatkan Produktivitas Karyawan. Jakarta: PT Pustaka Binaman Pressindo, 1993.

[3] D. Rohdiana. "Teh: Proses, Karakteristik \& Komponen Fungsional”. Foodreview Indonesia, vol. 10, no. 8, pp. 34-37, 2015.

[4] Badan Standarisasi Indonesia. SNI 1902:2016. Teh Hitam. Jakarta: Badan Standardisasi Nasional, 2016.

[5] D. F. Rosida dan D. Amalia. "KAJIAN PENGENDALIAN MUTU TEH HITAM CRUSHING, TEARING, CURLING”. J. REKAPANGAN, vol. 9, no. 2, pp. 59-73. 2015.

[6] M. A. Dermawan. "Penerapan Statistical Quality Control (SQC) Untuk Megidentifikasi Complain Customer pada PT Aerofood ACS Cabang Kualanamu". Tugas Akhir, Universitas Sumatera Utara, Medan, 2018.

[7] J. Heizer dan B. Render. Manajemen Operasi, Edisi 7. Jakarta: Salemba Empat. 2006.

[8] S. Assauri. Manajemen Pemasaran. Jakarta: Rajawali Press. 2004.

[9] D. W. Ariani. Pengendalian Kualitas Statistik. Yogyakarta: Andi Offset. 2004.

[10] B. Render dan J. Heizer. Prinsip-prinsip Manajemen Operasi. Jakarta: Salemba Empat. 2001. 